ments be made on every gas mixture employed. There are three bombs for experiments employing up to $200 \mathrm{~atm}$. initial pressure (Fig. 2) - the old bomb used by Prof. Bone at Leeds, a spherical bomb, and a cylindrical bomb with quartz windows for spectrographic work-and one, having 9-in. walls, wirewound, and protected by thick rope curtains (the best known device), for experiments at initial pressures up to $1000 \mathrm{~atm}$. (Fig. 3). This bomb is charged by a one-stage process with gas, and then by a two-stage process with air, in order to attain the requisite pressure ; the charging is controlled from a distance, and the gauges are observed in a mirror. All the large apparatus, with the exception of the new $1000 \mathrm{~atm}$. compressor, the compressor for catalytic experiments, and a few cylinders, which were made in Germany (from designs which, like those of most of the apparatus, were prepared by Dr. D. M. Newitt in consultation with Prof. Bone), are of British manufacture. Another new apparatus, with quartz windows, maintains steady continuous flames at pressures up to $100 \mathrm{~atm}$. Experiments on the catalytic production of methyl alcohol in a single-tube unit will be extended with a new plant having three vertical catalytic tubes operated under $1000 \mathrm{~atm}$. pressure at $600^{\circ} \mathrm{C}$. (Fig. 4).

\section{Photographic Study of the Development of Gaseous Explosions.}

Supported by Nobel's Explosives Co., Ltd., this work has included the investigation of phenomena associated with the initial stages of gaseous explosions, and the influence of 'shock waves' in speeding up combustion and developing detonation, and it is now being ex tended to that of the influence of strong electrical and magnetic fields on flame-propagation in gaseous explosions. A novel form of camera designed by Mr. R. P. Fraser, and constructed for these researches, attains a film-speed of 200 metres per sec. A similar camera has been sent to Messrs. Nobel's at Ardeer, and another is to be despatched to the Australian Government.

Combustion of Carbon Monoxide, etc.

With the aid of fellowships maintained by the Gas Light and Coke Co. and Radiation Ltd., the influence of moisture on the combustion of carbon monoxide has been shown to be essentially electronic. The limit of drying capacity of phosphorus pentoxide on a mixture of carbon monoxide and oxygen is attained in about 200 days, but however carefully dried, the two gases always explode if a sufficiently powerful spark is employed.

\section{Blast Furnace Reactions.}

These investigations, which are being carried out under the auspices of the National Federation of Iron and Steel Manufacturers, aim at studying each reaction fundamentally, and at the gas-speeds-up to 20 m.p.h.-actually obtaining in the blast furnace. In particular, the phenomenon of carbon-deposition, which occurs on interaction of ferrosoferric oxide and carbon monoxide, and at $450^{\circ}$ by the change $2 \mathrm{CO}=\mathrm{C}+\mathrm{CO}_{2}$, but not above $650^{\circ}$, is being followed up with the view, broadly speaking, of discovering whether or not the deposition should be encouraged, and what factors influence its appearance. Such knowledge is a positively essential preliminary to any marked chemical advance in the manufacture of iron, and the results will be of great value in the characterisation of ores. To acquire them is costing some $£ 1600$ per annum.

\section{Surface Action and Ionisation.}

Gaseous combustion in electrical discharges, and the electrical condition of surfaces during catalytic combustion, are under investigation. Work supported by the Department of Scientific and Industrial Research, and directed by Asst.-Prof. Finch, has already shown that combustion is conditioned by a prior 'ionisation' of both the combustible gas and oxygen.

\section{Chemical ENGINEERING.}

Prof. Hinchley's section of the Department, in addition to providing systematic post-graduate instruction in the operation of chemical plantinstruction in which special attention is given to costing and to the actual construction of suitable units - is, with the support of the Distillers' Company, engaged in investigating fundamental problems connected with heat transmission and filtration. As soon as space is available, and further equipment installed, it will be possible to attack more adequately and systematically from a fundamental point of view the many problems encountered in the design and operation of chemical plant.

\title{
The Henri Poincaré Institute in Paris.
}

IN November last a new institute of mathematics and mathematical physics was formally inaugurated in Paris. It was both the official opening of a new building and the beginning of new courses of lectures, all to be a part of the Faculty of Sciences of the University of Paris. The building is now ready, but the internal arrangements are not yet complete.

The history of the new institute is brief. It had been noted by the International Education Board that on several occasions it had given large sums of money to different universities in Europe and that gifts to French universities had been on a much smaller scale. The importance of the French mathematical school suggested that help might usefully be given to mathematics in France. The decision was taken after consultations in which Prof. Trowbridge, who represented the International Education Board, and Prof Birkhoff took leading parts. Prof. Émile Borel was asked to draw up a scheme. The plan, which was approved, provided for an institute to be named 'L'Institut Henri Poincaré,' as a centre for teaching and research on mathematical physics and the calculus of probabilities.

The courses on physical theories will be given in the new Institute by Prof. Léon Brillouin and M. Louis de Broglie. Prof. Léon Brillouin has made himself known by his researches on the theory of quanta and its applications; and he was invited last year to lecture in several universities of the United States and Canada. Dr. Louis de Broglie is one of the creators of wave mechanics, which now play a leading part in mathematical physics. These courses form an important addition to those already given in Paris by Prof. Brillouin and Prof. Langevin at the Collège de France, and by Prof. Eugène Bloch and Prof. Villat at the Sorbonne.

The calculus of probabilities already has its great exponent at the Sorbonne in Prof. Émile Borel. His researches on this subject have done much to revive interest in France in this subject, which owes so much to French workers such as Pascal, Fermat, Laplace, Poisson, Bienaymé, Cauchy, Cournot, Bertrand, Henri Poincaré. To Prof. Borel's course will now be added a new course by Maurice Fréchet, formerly professor of higher analysis at the University of Strasbourg. His theory of abstract spaces and functions has already made him known in the United States, where he delivered a course of lectures 
at the University of Chicago in 1924. More recently, he has devoted much attention to the theory of probability, on which he has published (in collaboration with Prof. Halbwachs) "Le calcul des probabilités à la portée de tous."

The Henri Poincaré Institute will not, however, confine its attention to the new courses. It aims at being international in scope; in addition to the regular courses, single lectures or brief series of lectures will be given by distinguished scientific workers. Profs. Vito Volterra, of Rome, and de Donder, of Brussels, have already promised to co-operate.

The ever-increasing numbers at the Sorbonne has made additional accommodation necessary, and it was decided to erect a new building where not only the new courses but also all the advanced courses on mathematics will be given and where the mathematical library will be moved. The International Education Board is contributing one hundred thousand dollars towards these expenses; Baron Edmond de Rothschild has also contributed twenty-five thousand dollars, and the French Ministry for Education three hundred thousand francs. It is thus hoped to create in Paris a great scientific international centre for mathematical physics and calculus of probabilities.

\section{Development and Morphology of Tunicates.}

A RECENT issue of the Quarterly Journal of Microscopical Science (vol. 72, pt. 1) is entirely occupied by two memoirs on Tunicata. In the first, on the development of Botrylloides and its bearings on some morphological problems, by Miss Sylvia Garstang and Prof. Walter Garstang, uniformity in the purely ectodermal origin of the Ascidian atrium is established, which finally negatives the homology suggested by Van Beneden and Julin (1887) between the larval atrial canals of Ascidians and the spiracles of Appendicularians.

The investigation of the neuro-hypophysial system shows that the anterior part of the neural tube in front of the sensory vesicle undergoes a conspicuous development, and becomes longitudinally differentiated into two parts - a large ventral precerebral lobe which disappears entirely before the tadpole stage is reached, and a slender dorsal precerebral duct which persists and agrees essentially with the hypophysial duct of other Ascidians. This duct communicates with the oral region of the pharynx by a ciliated funnel, and gives rise to the brain by proliferation from its ventral wall.

It would appear that a considerable development of the pre-sensory region of the neural canal and its glandular modification was a primitive feature of the Tunicata, and distinguished them from Amphioxus and the Vertebrata. The comparative morphology and significance of the precerebral lobe is fully discussed.

The second paper is by Prof. Garstang alone. It is an interesting and speculative essay on the morphology of the Tunicata and its bearings on the phylogeny of the Chordata. He regards the current views of Tunicate ancestry-that the tailed larva represents the primitive or ancestral form from which the adult has been evolved by degeneration-as untenable. The neuro-muscular relations in Ascidian larvæ and Appendicularians are much more consistent with a theory of incipient than of vestigial metamerism and the development of atria before the gill-slits is in accordance with the phyletic history of the Protochordate type of gill-slit. The discontinuity between larval and adult nervous systems ("it is an error to assert that any part of the actual nervous system of the adult has formed a part of the larval nervous system ") in Tunicates is unintelligible on the theory that Tunicates have been derived from Amphioxuslike ancestors, and points to a derivation of Tunicates from ancestors with a metamorphic life history before the typical chordate nerve-tube had come into existence.

The author has re-studied the symmetry of Amphioxus, which he explains as the consequence of the secondary reduction of yolk in the egg entailing premature hatching and the improvisation of a larval feeding mechanism. A great enlargement of the mouth and special ciliation of its entrance seem to form the basis of this mechanism, which involves a temporary dislocation of the adjacent parts and is held to have entailed changes which have left a mark on the permanent organisation of the adult. The author concludes that the ancestors of Amphioxus were essentially primitive Ascidians. In a future communication he proposes to deal with the origin of the chordate nervous system, and with the various cephalic organs associated with it.

\section{University and Educational Intelligence.}

London.-The Senate has accepted an offer of the Committee of the Bayliss-Starling Memorial Fund of the sum of $£ 2500$ for the establishment at University College of a scholarship for training in physiology and biochemistry, to commemorate the connexion with physiology of the late Sir William Bayliss and Prof. E. H. Starling.

The following doctorates have been conferred: D.Sc. (in anatomy) on Mr. H. A. Harris (University College), for a thesis in the form of a series of memoirs dealing with the problems of bone growth, radiology, and teratology, published in various medical and scientific journals; D.Sc. (in botany) on Mr. W. B. Turrill (Chelsea Polytechnic), for a thesis entitled "The Phytogeography of the Balkan Peninsula"; D.Se. (in chemistry) on Mr. Edgar Stedman (Birkbeck and Goldsmiths' Colleges), for a thesis entitled "The Relationship between Chemical Constitution and Physiological Action"; D.Sc. (in psychology) on Mr. J. C. Flugel (University College), for a thesis entitled "Studies in Mental Oscillation and Related Functions."

Dr. A. Sterling Parkes has been awarded the William Julius Mickle Fellowship for 1929 in respect of the work he has carried out during the past five years on the physiology and biochemistry of the organs of reproduction. The Fellowship this year is of the value of about $£ 250$.

Dr. G. P. Crowden has been appointed lecturer in applied physiology in the Division of Public Health at the London School of Hygiene and Tropical Medicine as from Aug. 1 .

In March last a committee was appointed "To consider the question of the limitations placed upon the Medical Education of Women Undergraduates and to report to the Senate thereon." This report has now been issued. The problem was to provide clinical facilities for women requiring them in schools open to both sexes. The report points out that the prepossession of the University is in favour of co-education in medicine as in all other faculties, and suggests that there should be three types of clinical education : (1) for men only, (2) for women only, and (3) for men and women. The Senate has given general approval to the report, and schools of medicine not at present admitting women are to be invited to admit a quota of women students.

THE annual meeting of the Association of Technical Institutions will be held at the Grocers' Hall, London,

No. 3092, VoL. 123] 